Prof. Suzana Bornarova, Asst Prof. Vladimir Ilievski

Institute for Social Work and Social Policy

Faculty of Philosophy - Skopje

\title{
IMPLEMENTATION OF LICENSING IN SOCIAL PROTECTION: Regional Achievements and Challenges
}

UDK: 364-43:331.108.37

\section{Licensing and its relevance to social work}

A license is a document (work permit) issued by an official body (most commonly chamber) to persons - professionals, institutions, programmes, projects. It is an instrument used by the state to supervise the entire process of development of the social protection, in terms of: adequate quality of the institutions; adequate operation of the institutions; adequate services delivered to beneficiaries; professional qualifications and development of professionals; continuing upgrading of the knowledge base (Bornarova, 2004).

Social work's interest in licensing issues reflects the profession's need to define itself and its role within a larger social protection system. Social work has increasingly attempted to define its role in relationship to other "helping professions" (Haynes, Mickelson, 2000). The movement to license social work represents an effort to organise and control practice. In part, it reflects the professional tendency toward gate-keeping, or restricting entry to a field. The types of legal regulation of social work vary, from certification (in which the use of the title "social worker" is limited to those with special knowledge and skills) to actual licensure (in which the state spells out specific requirements and limits the actual practice of social work to those meeting the requirements (Popple, Leighninger, 1993). In fact, social work is using a number of strategies to 
attain a higher professional status by protecting its domain against competitors. One of these strategies is to attain autonomy via selfregulation and vendorship of the profession. This strategy is also justified by a desire to protect the public against practitioners without appropriate qualifications. It intends to ensure consistent standards across settings and give clients recourse if those standards are not met. The future trend is to obtain licensing and vendorship and to continue to make more stringent practice requirements, such as continuing education, periodic recertification and period reviews of practice (Raffoul, McNeece, 1996).

The importance of licensing for social work is multiple:

- protection of service beneficiaries through introduction of minimum standards of services;

- increased competencies of social workers;

- advancement and professionalisation of social work as a profession;

- more transparent and more clear definition of the profession in the public and contribution to its independence;

- achievement of higher professional status;

- regulation and control of the private sector;

- distinguishing the role of social work from the other helping professions in the social protection domain;

- preservation of the professional identity of social workers and insight into their particular field within the social protection.

\section{Regional achievements in licensing in the domain of social protection}

\subsection{Licensing in the Republic of Macedonia}

In the Republic of Macedonia licensing in social protection was initially introduced in 2009. The responsible institution to manage this process is the Institute for Social Activities. This institution establishes a Licensing Commission; issues, renews, extends and withdraws work licenses of professionals from public and private social protection 
institutions; manages a registry of issued, renewed, extended and withdrawn licenses; carries out continuing education of professionals and tests the application of their professional knowledge, in the process of issuing licenses.

In terms of the conditions for issuing a license, a professional from a social protection institution with high education, can obtain a license if he/she:

- has high education with acquired minimum 180 ECTS credits or completed VII/1 degree;

- is a citizen and has residence in the Republic of Macedonia;

- is not charged with court prohibition of performing a profession or activity;

- had underwent at least 40 hours of education carried out according to the Programme for continuing education of professionals from the social protection institutions developed by the Institute for social activities.

- successfully passes the test for application of professional knowledge carried out by the Licensing commission.

An issued license is valid for 5 years. Three months before the validity of the license expires, a request is submitted to the Licensing commission for its extension. A professional with high education may renew a license if, within the period of the validity of the license had participated in at least 20 hours continuing education during one calendar year, and if the Licensing commission following testing procedures confirms that the professional successfully applies his/her professional knowledge(Rulebook on Modalities and Procedures for Issuing, Extending, Renewing and Withdrawing a License for Work of Professionals from Social Protection Institutions, Expenses for Issuing a License, Forms and Contents of the Work License, 2012).

The license for professionals from social protection institutions are being issued and renewed on the basis of testing during an examination applied to assess their professional knowledge. The exam is composed of two parts: 
1) First theoretical part - to assess theoretical knowledge of the professionals (through electronic computer-assisted test containing maximum 50 questions);

2) Second practical part - to assess the practical capabilities of professionals (through case studies).

The first theoretical part of the exam must be passed for the professional to be allowed to take the second practical part.

\subsection{Licensing in the Republic of Serbia}

Licensing in Serbia was introduced in 2012. Responsible institution to organise and manage the licensing process in the Republic of Serbia is the Chamber of Social Protection. It's activities related to licensing are the following:

- manages a registry of its membership (professionals and collaborators)

- organises and carries out the licensing examination in social protection;

- manages a registry of issued, renewed, extended and withdrawn licenses; and

- manages a registry of the costs for membership, issuing and extending a license, issuing legitimation documents and certificates.

Unlike the case in Macedonia where one general type of license is issued to all professional working in the domain of social protection, in Serbia a license is issued for: a) performing basic professional work in social protection (general license); b) performing specialised professional work in social protection (specialised license); c) performing supervisory work (supervisory license); and d) performing legal work in social protection (legal license).

In terms of the conditions to be fulfilled for issuing a license, all professionals and collaborators working in social protection are granted zero license if they fulfill the following criteria: 
- have acquired at least one year working experience in social protection;

- have beginner's or voluntary years of service, passed licensing exam, in case they are not employed in social protection;

- meet the basic conditions (completed high, graduate and postgraduate studies); and

- completed accredited programme for obtaining specific knowledge and skills for a concrete field of work and work with specific category of service beneficiaries(Rulebook on Licensing of Professionals in the Domain of Social Protection, 2013).

Validity of an issued license is 6 years, following which the license is renewed. A professional may renew the general, specialised and legal license if within the period of 6 years obtains minimum 120 points (of which $30 \%$ in the first 3 years after the license had been issued) from the points list. To renew a supervisory license, 40 points in supervisory theory and practice after the license had been issued, are required.

\subsection{Licensing in the Republic of Croatia}

Licensing in Croatia was introduced in 2013. It is a responsibility of the Chamber of social workers. This institution:

- establishes the conditions for performing independent work and withdrawing the license for this independent work;

- issues licenses for independent work of EU and other foreign citizens;

- withdraws and limits the performance of independent work;

- determines the price of services provided by social workers, masters of science in social work and masters of science in social policy, performing private practice of independent professional activity;

- manages a registry of social workers, masters of science in social work and masters of science in social policy. 
Stipulated conditions for issuing a license are the following:

- completed graduate/postgraduate studies in social work in Croatia;

- completed postgraduate studies in social policy in Croatia or in possession of recognised diploma from a foreign country;

- passed professional exam;

- knowledge of the Croatian language (spoken and written);

- registration at the Chamber of social workers directory.

- $\quad$ permit for performing independent work.

An issued license is valid for 6 years. Requirements for its renewal are: obtaining required number of points for professional upgrading (regulated with a separate act of the Chamber) and submitting request for extension of the permit for performing independent work 3 months before the expiration date. The Chamber's President is obliged to respond to the applicant for extension of the license in a period not longer than 30 days.

\section{Challenges}

The introduction of licensing of professionals engaged within the social protection systems in the region is new but important reform process aimed at making a positive step forward towards advancing professional capacities in the social protection domain. However, this process is followed by numerous challenges yet to be overcome.

Initial legislative changes required for introduction of licensing have been accompanied by different reactions on the part of professionals, most commonly in a form of initial resistance and skepticism towards various aspects of the licencing, such as: justification of the selected managing institutions; modalities of organisation and implementation of the process itself; possibilities and challenges related to professional development of those employed in social protection; impact of the licensing on enhancing and increasing their professional competencies; as well as impact of licensing on improvements of social services delivered to service beneficiaries. In addition to this initial resistance, some form of uncertainty has also been present on the part of managing institutions and 
established commissions. This is predominantly a result of the lack of previous practical experience in licensing, insufficiently regulated legal framework, as well as due to challenges related to preparation and modalities of implementation. Also, the current commissions should be enlarged and enhanced with additional membership coming from distinguished and eminent professionals from different social institutions, to be able to adequately assess professional competences of candidates.

Given the fact that the trend of pluralism in social protection has been widely accepted in the region and it entailed inclusion of numerous service providers from other sectors in addition to the public one, there is a need for extending coverage with licensing to all service providers in the domain of social protection, including professionals from nongovernmental and private service providers. In the case of Serbia and Croatia, licensing should also cover all the other professionals who are not members of the Chambers.

Recognition of professional training, participation at conferences, debates, round tables, publications and other forms of professional upgrading is also required, as well as more precise regulation of the complete licensing procedure (including the professional examination).

If we take into consideration that there are different professionals engaged in the domain of social protection, whose specialty are different service beneficiaries, there is a need for specialisation of licensing per profiles of workers as well as specialisation of licensing per categories of beneficiaries.

Last but not least, engagement of the high-education institutions in programmes and trainings required to obtain a social protection license is also a challenge. Given the importance of continuing professional education to raising the levels of skills, competences and knowledge of professionals, high education institutions should be involved not only in the design and development of contemporary training programmes but in their implementation as well. 


\section{References}

Bornarova, S. (2004). Licence - A Path Toward Professionalisation of Social Services. Annual of the Faculty of Philosophy Vol. 57.

Chamber of Social Workers of Croatia (2012). Rulebook on the Procedures for Registering Members of the Croatian Chamber of Social Workers.

Haynes, S., K., Mickelson, S., J. (2000). Affecting Change: Social Workers in the Political Arena. Allyn and Bacon.

Managing Board of the Chamber of Social Workers of Croatia (2013). Rulebook on the Procedures for Issuing, Renewing and Withdrawing Independent Work Permits.

Official Gazette of the Republic of Macedonia No. 04/12. Rulebook on Modalities and Procedures for Issuing, Extending, Renewing and Withdrawing a License for Work of Professionals from Social Protection Institutions, Expenses for Issuing a License, Forms and Contents of the Work License.

Official Gazette of the Republic of Macedonia No. 79/2009, 36/2011, 51/2011, $166 / 2012,15 / 2013,79 / 2013,164 / 2013,187 / 2013$ и 38/2014. Law on Social Protection.

Official Gazette of the Republic of Serbia No. 24/2011. Law on Social Protection.

Official Gazette of the Republic of Serbia No. 42/2013. Rulebook on Licensing of Professionals in the Domain of Social Protection.

Official Gazette of the Republic of Croatia No. 124/11. Law on Social Work Activities.

Official Gazette of the Republic of Croatia No. 157/13. Law on Social Protection.

Popple, R., P., Leighninger, L. (1993). Social Work, Social Welfare and American Society. Allyn and Bacon.

Raffoul R., P., McNeece, A., C. (1996). Future Issues for Social Work Practice. Allyn and Bacon. 